\title{
Situs Inversus \& Adult Polycystic Kidney Disease
}

\author{
M Nauman Hashmi*, Tanzeel Abbasi, Rashid Asghar, Khurram Bashir and Ruqayya Basharat \\ Department of Nephrology, Multan Institute of Kidney Disease, Multan
}

*Corresponding author: M Nauman Hashmi, Department of Nephrology, Multan Institute of Kidney Disease, Multan

\begin{abstract}
Situs Inversus totalis is rare disorder in which there is transposition of organs position. Polycystic kidney disease is a disorder in which water containing cysts are formed in kidneys. Though named as polycystic kidney disease but cysts are formed in other organs such as liver, pancreas, seminal vesicles \& arachnoid membrane. Association of these two conditions is rare.
\end{abstract}

\section{Introduction}

Situs Inversus \& polycystic kidney disease combination is a rare entity. Recent research suggests ciliary abnormalities is root cause of both conditions.

\section{Case}

A 45-year-old male presented to emergency with complaints of backache, left flank pain \& blood in urine for 1 week. Patient is the third child of consanguineous parents and has 6 brothers and 3 sisters. One sister is known to have renal disease secondary to NSAIDS abuse. He is married and father of six children with eldest daughter of 14 years of age. He is an occasional smoker. He had no history of sinusitis or repeated chest infections. On physical examination, apex beat was palpable in the right 5 th intercostal space in mid clavicular line. The cardiac dullness was on the right side and the heart sounds were similarly disposed. Abdomen was soft and the liver was palpable in left hypochondrium. Patient had bilateral palpable kidneys on bimanual palpation. On admission, his blood reports $\mathrm{Hb} 12.1 \mathrm{gm} / \mathrm{dl}$, Corrected Ca $6.2 \mathrm{mg} / \mathrm{dl}$, Serum Creatinine $14.1 \mathrm{mg} / \mathrm{dl}$. Chest x-ray obtained during admission (Figure 1), revealed dextrocardia and raised suspicion of situs inversus totalis. CT abdomen (Figure 2) showed situs inversus totalis of all the abdominal organs and bilateral enlarged kidneys with multiple renal cysts of variable sizes and densities. Hepatic cysts were also seen. No detectable abnormality was seen in lung fields. All of these findings were compatible with those of end stage renal disease due to autosomal polycystic kidney disease (ADPKD). Patient required emergent hemodialysis total five dialysis session were done during stay in hospital \& was discharged on maintenance hemodialysis. 


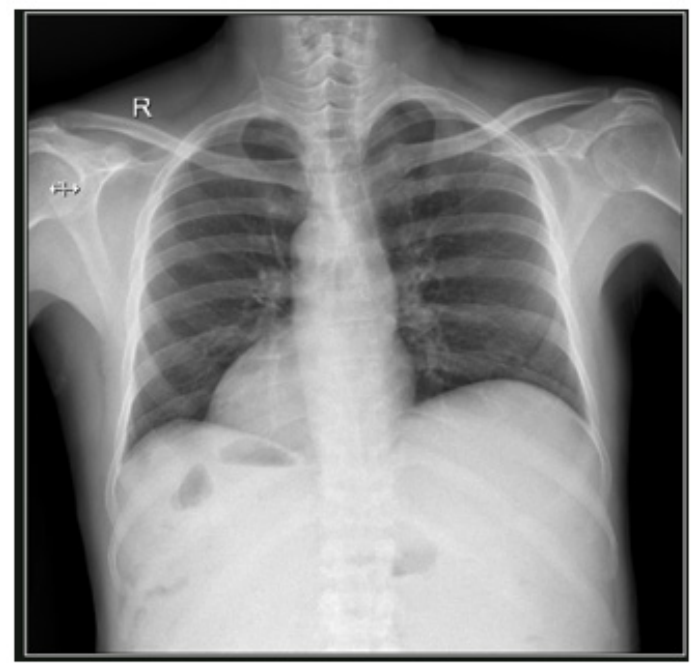

Figure 1: Chest X-ray showing dextocardia.

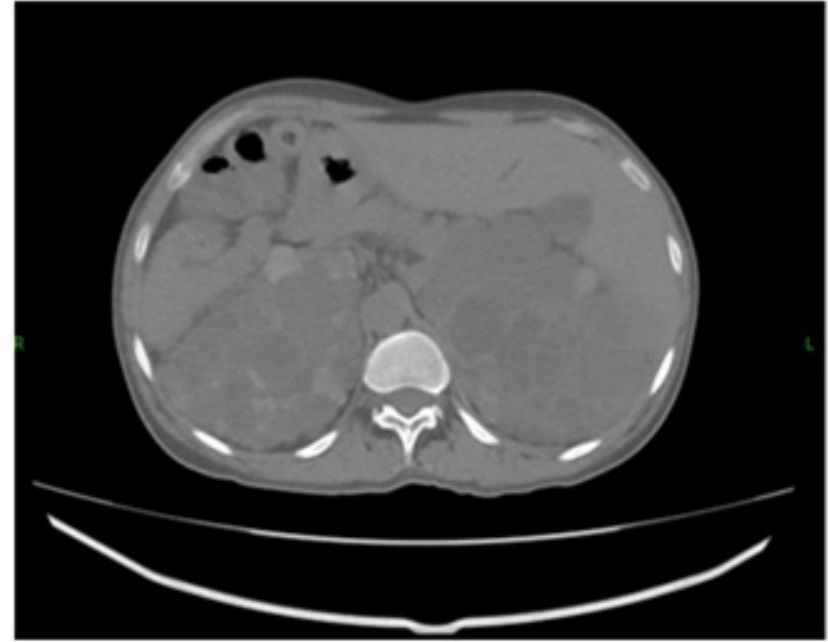

Figure 2: Ct scan showing Bilateral Polycystic kidneys and Left sided Liver.

\section{Discussion}

Human organs orientation in $99.99 \%$ individuals is with left sided heart, liver in right hypochondrium \& spleen in left. Rarely this pattern is disturbed which can range from single organ disarray called situs solitus to situs inversus totalis where there is complete reversal of normal organ orientation [1]. Hieronymus Fabricius, known also by Latin \& Italian names, Fabricius ab Aquapendente or Girolamo Fabrizi d'Acquapendente, first described disorders of laterality. A historical survey shows a case of reversed liver and spleen reported by Fabricius in 1600 [2]. After discovery of laterality in 1600, in 1903 primary ciliary defect was reported by A.K Zivert and later by Kartagener in 1933.This founded the root for further research to look for connection between situs inversus \& cystic kidney disease $[3,4]$. At that time nobody was aware that two types of cilia would be involved in laterality development and that genes causing cystic kidney disease would play a role [5]. In last 4 decades a lot of groundbreaking work has been done in this regard. First theory of lack of dynein arm was put down as cause of immotile cilia, then two cilia model was purposed and later few genes have been labelled for heterotaxy such as GALNT 11 [6].

\section{Conclusion}

We are reporting a patient with situs inversus totalis \& polycystic kidney disease which is a rare combination though hypothesis purpose a common underlying defect.

\section{Acknowledgement}

None.

\section{Conflict of Interest}

No conflict of interest. 


\section{References}

1. Aylsworth AS (2001) Clinical aspects of defects in the determination of laterality. Am J Med Genet 101(4): 345-355.

2. Sutherland MJ, Ware SM (2009) Disorders of left-right asymmetry: heterotaxy and situs inversus. Am J Med Genet C Semin Med Genet 151C (4): 307-317.

3. Kartagener M (1933) Zur Pathogenese der Bronchiektasen Mitteilung Bronchiektasien bei Situs viscerum inversus Beitr Klin Tuberk 83: 489501.
4. Glang E (1904) Geburtshindernis infolge von beiderseitigen Cystennieren verbunden mit Pancreascyste und situs inversus Universität Leipzig Doctoral dissertation.

5. McGrath J, Somlo S, Makova S, Tian X, Brueckner M (2003) Two populations of node monocilia initiate left-right asymmetry in the mouse. Cell 114(1): 61-73.

6. Fakhro KA, Choi M, Ware SM, Belmont JW, Towbin JA, et al. (2011) Rare copy number variations in congenital heart disease patients identify unique genes in left-right patterning. Proc Natl Acad Sci U S A 108(7): 2915-2920. 